Provided for non-commercial research and education use. Not for reproduction, distribution or commercial use.

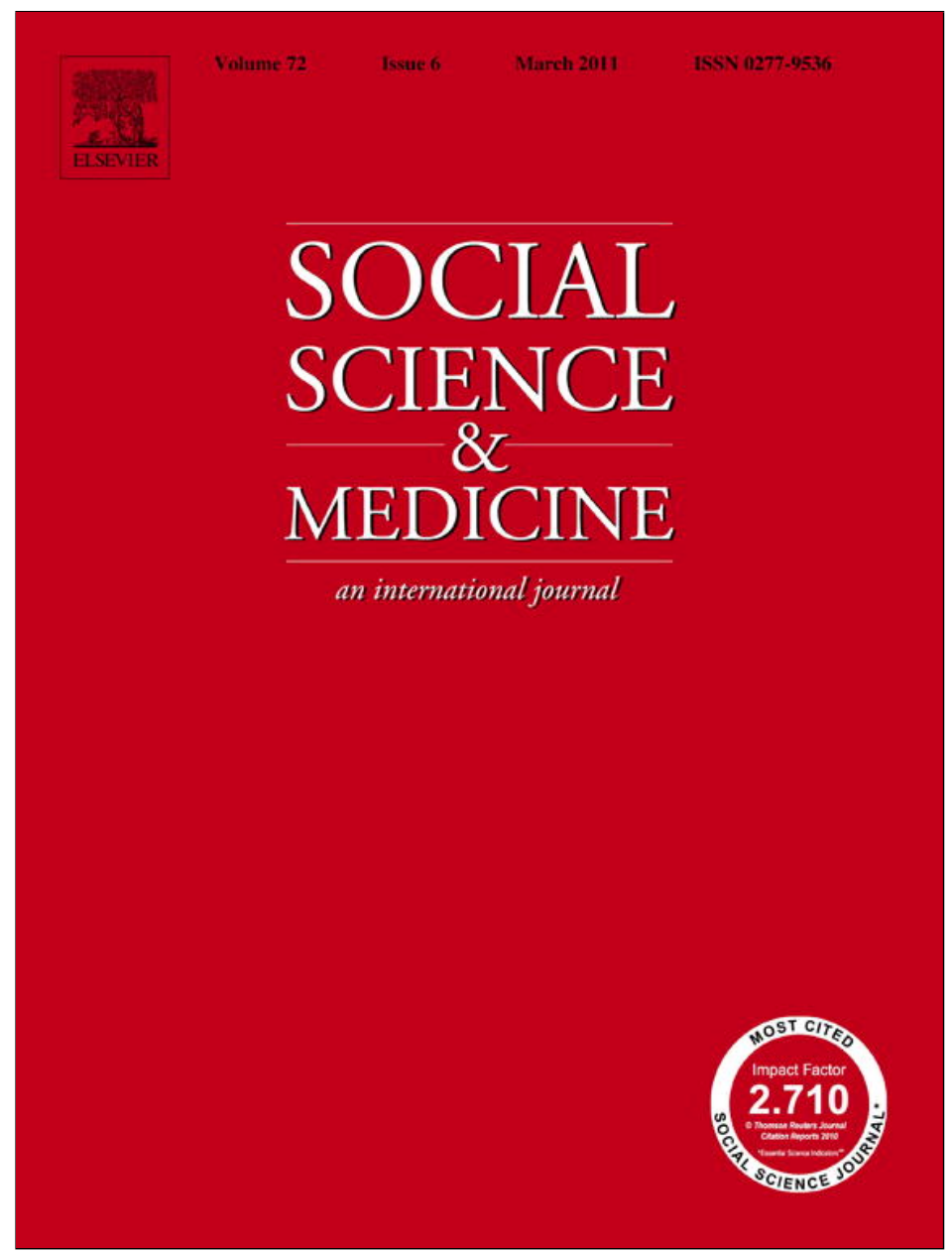

This article appeared in a journal published by Elsevier. The attached copy is furnished to the author for internal non-commercial research and education use, including for instruction at the authors institution and sharing with colleagues.

Other uses, including reproduction and distribution, or selling or licensing copies, or posting to personal, institutional or third party websites are prohibited.

In most cases authors are permitted to post their version of the article (e.g. in Word or Tex form) to their personal website or institutional repository. Authors requiring further information regarding Elsevier's archiving and manuscript policies are encouraged to visit:

http://www.elsevier.com/copyright 


\title{
Do pharmaceuticals displace local knowledge and use of medicinal plants? Estimates from a cross-sectional study in a rural indigenous community, Mexico
}

\author{
Peter Giovannini ${ }^{\mathrm{a}, \mathrm{b}, *}$, Victoria Reyes-García ${ }^{\mathrm{c}}$, Anna Waldstein ${ }^{\mathrm{b}}$, Michael Heinrich ${ }^{\mathrm{a}, \mathrm{b}}$ \\ ${ }^{a}$ Centre for Pharmacognosy and Phytotherapy, The School of Pharmacy, University of London, 29-39 Brunswick Sq., London WC1N 1AX, UK \\ ${ }^{\mathrm{b}}$ School of Anthropology and Conservation, Marlowe Building, University of Kent, Canterbury, Kent CT2 7NR, UK \\ ' ICREA and Institut de Ciència i Tecnologia Ambientals, Universitat Autònoma de Barcelona, 08193 Bellatera, Barcelona, Spain
}

\section{A R T I C L E I N F O}

\section{Article history:}

Available online 31 January 2011

\section{Keywords:}

México

Mazatecs

Traditional medicine

Medicinal plants

Pharmaceuticals

Self-treatment

Ethnobotany

\begin{abstract}
A B S T R A C T
Researchers examining the relationships between traditional medicine and biomedicine have observed two conflicting tendencies. Some suggest that the use of biomedicine and biomedical concepts displaces the use of traditional medicine and medical beliefs. Other scholars have found that traditional medicine and biomedicine can co-exist, complement, and blend with each other.

In this paper we use an econometric model and quantitative data to test the association between individual knowledge of pharmaceuticals and individual knowledge of medicinal plants. We use data from a survey among 136 household heads living in a rural indigenous community in Oaxaca, Mexico. Data were collected as a part of long term fieldwork conducted between April 2005 and August 2006 and between December 2006 and April 2007. We found a significant positive association between an individual's knowledge of medicinal plants and the same individual's knowledge of pharmaceuticals, as well as between her use of medicinal plants and her use of pharmaceuticals. We also found a negative association between the use of medicinal plants and schooling. Our results suggest that, in the study site, individual knowledge of medicinal plants and individual knowledge of pharmaceuticals co-exist in a way which might be interpreted as complementary. We conclude that social organization involved in the use of medicines from both traditional medicine and biomedicine is of particular significance, as our findings suggest that the use of pharmaceuticals alone is not associated with a decline in knowledge/use of medicinal plants.
\end{abstract}

(C) 2011 Elsevier Ltd. All rights reserved.

\section{Introduction}

Understanding whether and how traditional medicine [here defined as "the sum total of knowledge, skills and practices based on the theories, beliefs and experiences indigenous to different cultures that are used to maintain health, as well as to prevent, diagnose, improve or treat physical and mental illnesses."(WHO, 2008)] and biomedicine (here defined as a global, hegemonic medical system based on western scientific principles which includes the use of pharmaceuticals, healthcare professionals and biomedical facilities) complement or compete with one another has direct application in instructing effective policy for improving health care systems in developing countries, which still rely heavily on traditional medicine

\footnotetext{
* Corresponding author. Centre for Pharmacognosy and Phytotherapy, The School of Pharmacy, University of London, 29-39 Brunswick sq., London WC1N 1AX, UK. Tel.: +44 207753 5844; fax: +44 2077535909 .

E-mail address: peter.giovannini@gmail.com (P. Giovannini).
}

(WHO, 2008). The relationships between traditional medicine and biomedicine, that develop when different worldviews meet, are an important topic of debate in medical anthropology, medical ethnobotany, and health care development (Calvet-Mir, Reyes-García, \& Tanner, 2008; Etkin, Ross, \& Muazzamu, 1990; Hoa, Chuc, \& Thorson, 2009; Muela, Ribera, Mushi, \& Tanner, 2002; Scrimshaw \& Cosminsky, 1980; Vandebroek et al., 2004). At least two conflicting tendencies regarding this relationship have been documented. According to some researchers traditional medicine and biomedicine may be incompatible and the use of biomedicine and biomedical concepts often displaces the use of traditional medicine and medical beliefs (Ackerknecht, 1942; Foster \& Anderson, 1978; Ngokwey, 1995; Saethre, 2007). In contrast, other scholars have found that traditional medicine and biomedicine can co-exist, complement and blend with each other (Byg, Salick, \& Law, 2010; Etkin et al., 1990; Muela et al., 2002; Scrimshaw \& Cosminsky, 1980).

In this paper we examine the relationships between traditional medicine and biomedicine in a rural indigenous community in Oaxaca, Mexico, by focusing on knowledge and use of local 
medicinal plants (central to what is called traditional medicine) and knowledge and use of commercial pharmaceuticals and supplements (a key aspect of biomedicine, hereafter broadly referred to as pharmaceuticals).

In the remainder of this section, we briefly review recent studies that have found (a) a mutually exclusive relationship between knowledge of traditional medicine and biomedicine and (b) a relationship of co-existence and syncretism between traditional medicine and biomedicine. Following a description of the research site we test the following hypotheses:

(1) laypeople who hold more knowledge of pharmaceuticals hold less knowledge of medicinal plants and

(2) laypeople who use more pharmaceuticals use fewer medicinal plants.

Our work provides a methodological improvement insofar as we measured quantitatively both knowledge and use of medicinal plants and pharmaceuticals at the same time and unit of analysis (individual). Moreover, we included several control variables in our model and used an instrumental variable to control for possible reverse causality, omission of important third variables, and random measurement error (Angrist \& Krueger, 2001).

\section{Mutual exclusion and competition between traditional medicine} and biomedicine

Historically, in medical anthropology there was a focus on conflict between biomedicine and traditional medicine (Ackerknecht, 1942; Foster \& Anderson, 1978; Ngokwey, 1995; Saethre, 2007). For example, most literature on Australian Aboriginal medicine supports the idea that this medical system is incompatible with biomedicine (Saethre, 2007). Studies analyzing the results of education programs on specific health problems have stressed the role of traditional medicine as a barrier for the introduction of the new biomedical knowledge. Hoa et al. (2009) conducted a survey with 12,143 people living in a rural district in Vietnam to assess their knowledge about tuberculosis (TB). Despite the effort to introduce biomedical information on $\mathrm{TB}$, traditional beliefs about etiology were a strong barrier for knowledge acquisition, and only $15 \%$ of the respondents knew that TB is caused by bacteria.

Ethnobotanists have also argued that the increasing use of pharmaceuticals is a major determinant of the decreasing use and loss of knowledge of medicinal plants among indigenous populations (Caniago \& Siebert, 1998). Access to and use of biomedical health care may disrupt the dissemination of traditional medicine (Ragupathy, Steven, Maruthakkutti, Velusamy, \& Ul-Huda, 2008). Thus, in the conflict between traditional medicine and biomedicine the latter seems to displace the former, at least in some parts of the world.

Despite these assumptions, few studies have collected quantitative data to test the association between both traditional medicine and biomedicine. Vandebroek et al. (2004) measured both knowledge and use of medicinal plants and pharmaceuticals in six communities in the national park Isiboro-Sécure in the Bolivian Amazon. A village's physical isolation and distance from a primary health care service with a medical doctor were positively associated with knowledge and use of medicinal plants and negatively associated with the use of pharmaceuticals. They also found a negative association between medicinal plants knowledge and the use of pharmaceuticals at the community level. They concluded that where people were exposed and had access to pharmaceuticals and other forms of biomedicine, they were more likely to adopt them and reduce/discontinue the use of medicinal plants.
Co-existence and syncretism between biomedicine and traditional medicine

Some authors have suggested that traditional medicine and biomedicine, although perceived as discrete and separate bodies of knowledge, complement rather than compete with each other. For example, in a study conducted among Tsimane' Amerindians living in Amazonian Bolivia, Calvet-Mir et al. (2008) asked 39 informants to sort 20 medicinal plants and pharmaceuticals according to their similarities. They found that Tsimane' recognize these medicines as two discrete groups, suggesting that Tsimane' conceptualize the two types of medicine as "two independent domains of knowledge" (Calvet-Mir et al., 2008: 9). However, Tsimane' laypeople use both kinds of medicine when they are sick, and biomedical practitioners and traditional healers both expressed a willingness to work with one another, suggesting that cooperation between traditional medicine and biomedicine is possible. Similarly, Spring (1980) interviewed more than 300 Luvale women in rural Northwest Zambia. While her informants chose between traditional and biomedical options based on their faith in one system or the other, the use of traditional medicine and biomedicine sometimes was exclusive and sometimes was complementary.

In contrast to the theory of discrete domains of knowledge, several authors have suggested that traditional knowledge can integrate and/ or be integrated into recently acquired knowledge of biomedicine (see Byg et al., 2010). Muela et al. (2002) investigated local knowledge about malaria in two rural communities in Tanzania. They found that in some cases introduced biomedical information merged with preexisting local concepts instead of displacing them. For example, in a survey carried out with 220 women, $62 \%$ of them shared an interpretation of the disease etiology that is the result of syncretism of traditional medical beliefs and the introduced biomedical model. Thus, even if biomedical health messages are well understood, the meanings given to them may be different from those health workers intended, as they are reinterpreted through the traditional medical beliefs.

Similarly, in a study that focused on the medical pluralism of a Guatemalan plantation, Scrimshaw and Cosminsky (1980) found that folk practitioners frequently combined elements from both traditional medicine and biomedicine in their treatment of patients. These authors stress the adoption and adaptation of elements from both domains of knowledge. In a study conducted in a Hausa-Fulani community in Nigeria, increased access to and use of pharmaceuticals did not replace local disease concepts and the use of medicinal plants (Etkin et al., 1990). Rather, the introduced pharmaceuticals were used by Hausa according to local medical beliefs, a phenomenon that Etkin names "indigenization of pharmaceuticals" (Etkin et al., 1990: 919).

Both the conceptualization of traditional medicines and biomedicines as discrete but complementary domains and the hybridization of the two types of medicines are made possible by and contribute to medical pluralism (i.e. the existence of multiple theories of illness/disease and corresponding therapeutic strategies in a single society). Kleinman (1980) suggested that a society's healthcare system is not only made up of traditional and biomedical practices, but is also composed of different sectors (i.e. popular, folk and professional) with different therapeutic options. The work we describe in this paper focuses on popular medical knowledge and self-treatment with medicinal plants and pharmaceuticals and as such represents only one of many dimensions of medical pluralism in Mexico.

\section{Methods}

\section{The study site}

The Mazatecs inhabit the Sierra Mazateca, a region located in the north-eastern part of Oaxaca between the borders of the states of 


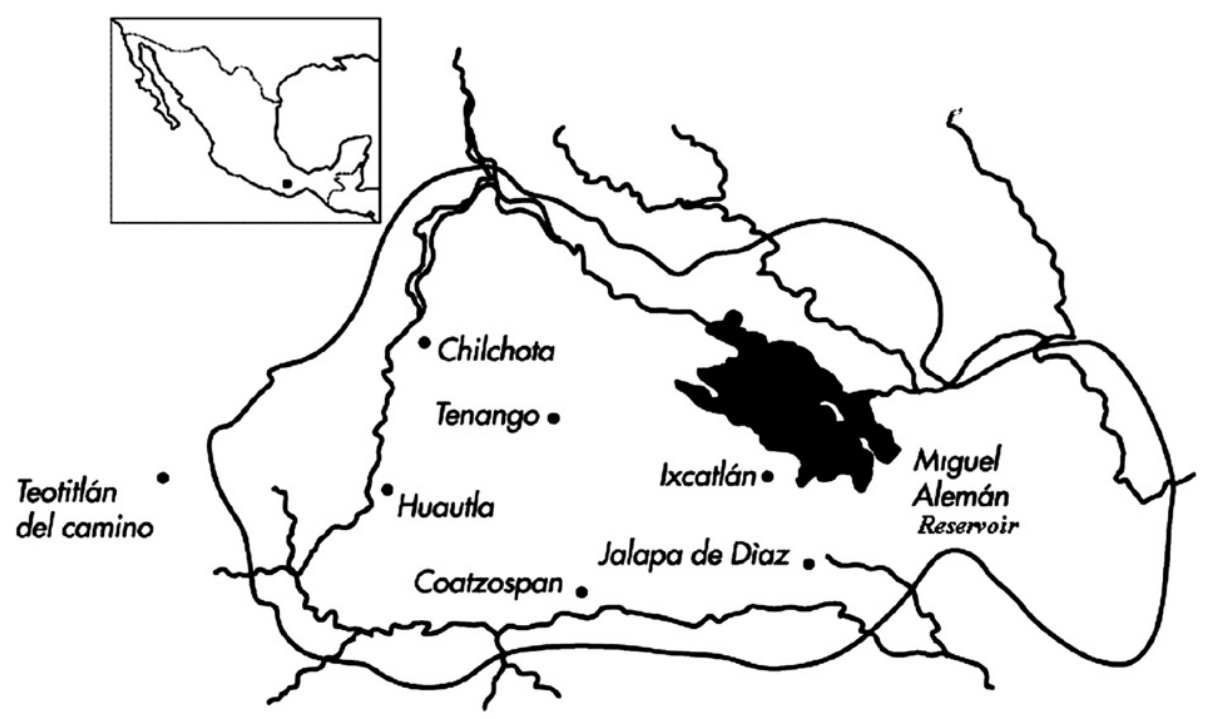

Fig. 1. Map of the Sierra Mazateca region. The line around the region delimits the borders of the Sierra Mazateca. Modified after (Cabrera, Inchaustegui, Garcia, \& Toledeo, 2001).

Puebla and Veracruz, Mexico (Fig. 1). This is a highly biodiverse region with ecological habitats varying from temperate to tropical and to cloud forests. The population is spread throughout communities with great variation in their level of market integration. Huautla de Jiménez (referred as Huatla in Fig. 1) is the main Mazatec urbanized center, where the impact of modernization on traditional lifestyle is evident. The Mazatec native language is spoken by a high percentage of the population, especially in the more remote communities (Boege, 1988).

Basic biomedical assistance (consisting of national vaccination campaigns, consultation with doctors, and dispensation of some medicines) is provided by small government health clinics spread over the Sierra Mazateca.

This study was conducted in a community of about 400 people in the municipality (municipio) of San José Tenango. We will refer to this community as "Paloma Alta" (This is a pseudonym). Paloma Alta is about 800 m.a.s.l. and at the time of this study was accessible only by hiking for about one and a half hours from the nearest dirt road, which connects the surrounding village of Cañada de Mamey with San José Tenango. In Paloma Alta everyone speaks Mazatec as a first language and few individuals are also fluent in Spanish, the Mexican national language. The main productive activities in Paloma Alta are the cultivation of corn, beans, and coffee, the last one being the main source of cash. At the time of the research, the average individual annual income earned from coffee was about 2388 Mexican pesos (US\$ 188.2, March 2010). Other sources of cash are subsidies distributed by the Instituto Mexicano del Seguro Social (IMSS), the Solidaridad scheme (a Mexican government scheme to help poor rural households), cash earned through trade, and remittances sent by relatives living in the Mexican urban centers such as Mexico City and Puebla.

In Paloma Alta, pharmaceuticals are considered expensive and in some cases are unaffordable. The nearest government hospital, where free patient care is offered, is located in Huatla de Jiménez, which is about $2 \mathrm{~h}$ drive by pickup from San José Tenango. In 2006, traveling to Huatla de Jiménez from San José Tenango cost 25 Mexican pesos (2.0 US \$). Respondents often cited costs among the reasons that prevented them from getting medical assistance in the hospital. The nearest public health clinic, which provides health services for the uninsured, is located in Cañada de Mamey. The nearest pharmacy is located in the municipal capital, San José Tenango, although traders sell some pharmaceuticals in community shops (tiendas) - generally simply a space of their house open to the path.

\section{Data collection and variables construction}

Fieldwork was carried out by the first author between April 2005 and August 2006 and between December 2006 and April 2007 as part of his doctoral studies. The first author followed the guidelines of the international Society of Ethnobiology, the American Anthropological Association and the institutional internal requirements for ethical review as they were in place in 2004. As a UK-based comparatively small institution, institutional ethical approval was not obtained for the study as no Internal Institutional Review Board existed at this time (it was implemented in 2008) and only studies involving the UK's NHS facilities or other health care providers were subject to an ethical review by the appropriate external bodies (like the NHS Trusts' review boards). Permits for research were obtained from Mexican authorities (Mexican Embassy in Italy, Oaxaca Immigration Office, Mexican Ministry of Environment and Natural Resources, and municipality of San José Tenango). Verbal community consent to carry out the research was granted during a community meeting where the research aim and methods were explained to the adult population. Further verbal individual informant consent was asked prior to each interview. Research progress and results were discussed periodically with community leaders. A bilingual translator assisted in interviews with monolingual informants in the Mazatec language. Voucher specimens were stored in the National Herbarium of Mexico and at the Instituto Mexicano del Seguro Social. Duplicates, when available, were stored at the herbarium of the School of Pharmacy, University of London.

\section{Background ethnographic data}

During the first phase of the research (15 months) we collected data on general concepts of health and sickness and on the medicinal plants and pharmaceuticals used in the study site through participant observation, open, semi-structured and structured interviews with most of the adult population in the study site (Berlin \& Berlin, 2005).

To produce a list of the most commonly used medicinal plants, we asked 33 respondents to list all the medicinal plants they knew. Similarly, we asked 43 respondents to list all the pharmaceuticals they knew. Freelisting interviews of the two cultural domains were carried out with a convenience sample. Most of the respondents 
participated in only one of the two different freelisting exercises. We deemed it unnecessary to elicit the freelisting of the two domains from the same persons, as our aim was to define the items that belong to the two cultural domains at the community level.

We followed standard ethnobotanical guidelines for the collection identification and storage of plant specimens (Martin, 2004) and collected data on the range of medicinal uses associated with each plant species.

\section{Survey and sample}

During the second phase of the research, we used the data collected during the first 15 months of ethnographic work as a basis to design a structured questionnaire. We used the questionnaire to collect systematic data through a survey that included questions on 1) knowledge and use of medicinal plants, 2) knowledge and use of pharmaceuticals, and 3) demographic and socioeconomic characteristics of informants. Our sample included all the male $(n=66)$ and female $(n=70)$ household heads of Paloma Alta who were 20 years of age or older and willing to participate $(n=136)$. The sample represents about $80 \%$ of the household heads living in the study community at the time of the survey and includes the informants who participated in open interviews and freelisting in the previous phase of the research. Below we discuss how we defined and measured our variables.

Dependent variable: knowledge and use of medicinal plants. To measure respondents' knowledge of medicinal plants, we used a true/false questionnaire. We could collect herbarium specimens of 65 of the 82 species of plants whose medicinal uses were documented during the first stage of the research. In order to design a questionnaire that contains questions with different degrees of difficulty, we randomly selected 15 species from the list of plants from which we had vouchers and mounted a dried specimen of each of the selected species (Appendix 1). We showed informants the 15 mounted specimens and asked them to provide the local (Mazatec) name of the species. If the informant could not name the dried specimens we prompted with its local name. Using both the dried specimens and the local name ensured a correct identification of the species before asking the questions on the uses of the plants and avoided misidentification due to the fact that folk botanical taxonomies can have several terms for the same species and several species can be recognized with the same term (Berlin, 1992).

If the informant identified the plant (either before or after having been prompted with its native name), we asked three true/ false questions about the use of each of the 15 species $(3 \times 15=45$ questions). For example, we asked "is this plant good to cure fever?", or "is this plant good to cure diarrhea?" We designed the questionnaire to include questions on uses that were clearly considered "right" or "wrong" at community level according to the data on the range of use of medicinal plants collected in the first 15 months of research.

If the informant did not identify the medicinal plant from the dried specimen nor after having been prompted with its native name, the questions on its uses were skipped and coded as "I do not know". To measure the use of medicinal plants we also asked respondents whether they had ever used each of the 15 selected plants for medicinal purposes. We coded affirmative answers as 1 , negative as 0 , and "I do not know" as 2 .

To calculate individual scores of medicinal plants knowledge, we first elaborated an answer key to our test based on the ethnographic information collected during the first phase of fieldwork. We then matched respondents' answers to the answer key. Our methodology builds from the findings of previous research that showed that, in spite of some intra-cultural variability (Boster,
1985), ethnobotanical knowledge is shared within an ethnic group and even more within inhabitants of the same community (Reyes-García et al., 2003). We corrected respondents' answers for guessing using Eq. (1) (Angoff \& Schrader, 1984), where the corrected scores $(S)$ depend on the number of correct answers $(R)$, wrong answers $(\mathrm{W})$, and on the number of options $(k)$ given to the informants for each question:

$$
\mathrm{S}=\mathrm{R}-[\mathrm{W} /(k-1)]
$$

We used the number of species each informant reported to have used in the past as medicine as an indicator of the overall use of medicinal plants. We validated the internal consistency of our tests for measuring knowledge and use of medicinal plants by calculating Cronbach's alpha (Bland \& Altman, 1997).

Explanatory variable: knowledge and use of pharmaceuticals. To measure individual knowledge of pharmaceuticals, we selected 14 pharmaceuticals (Appendix 2) from an initial list of 81 obtained through free listing. We arbitrarily selected the items with the following two criteria: 1) all the pharmaceuticals in the list had clear uses according to the consulted biomedical sources; 2) the items selected represent a continuous range from commonly to rarely used pharmaceuticals. We asked informants three true/false questions about the uses of each pharmaceutical $(14 \times 3=42$ questions). The pharmaceuticals were not shown during the interviews and the answers were prompted using pharmaceuticals' commercial names as previously elicited during freelisting. We used the commercial names of the pharmaceuticals because the first phase of this research showed that these were unambiguous. To estimate the use of pharmaceuticals by respondents, we asked whether the informant had ever used each of the 14 pharmaceuticals in the list. We coded affirmative answers as 1 , negative as 0 , and "I do not know" as 2.

To calculate individual scores of pharmaceutical knowledge we first elaborated an answer key to our test based on biomedical literature (Carranza, 2005; Swiss Pharmaceutical Society, 2004; UNAM, 2007) and then matched respondents' answers to this answer key. We corrected respondents' answers for guessing using Eq. (1).

An estimate of the use of pharmaceuticals was calculated summing up all the positive answers to the questions: "Have you ever used [pharmaceutical commercial name]?" This score was used as a proxy for use of pharmaceuticals. We assessed the internal consistency of our tests for measuring knowledge and use of pharmaceuticals by calculating Cronbach's alpha.

Demographic and socioeconomic characteristics of informants. We collected measures of each individual's age, sex, education, fluency in the national language, and cash income. We estimated the age of informants using the birth date recorded in the local health center, which is based on birth certificates. For individuals under 50 years of age, we considered the birth certificate accurate with a margin of error of weeks. For individuals older than 50 years of age the date of birth may be less accurate as birth certificates were not widely requested in the area at that time. We took note of the respondent's sex at the beginning of the interview and we coded males as 1 and females as 0 . Schooling was measured as number of school years completed as reported by the informant. The interviewer assessed the Spanish level of the informants during the survey and assigned a score using a 3-point scale ( $0=$ no Spanish; $1=$ basic level; 2 = fluent). We also included cash income as control for market integration. Individual cash income was proxied through the cash earned through the annual sale of coffee beans during the 12 months previous to the interview. 
Finally, we proxied maternal knowledge of pharmaceuticals by asking informants: "how knowledgeable was your mother on pharmaceuticals?" and assigned a score using a 4-point scale $(0=$ not at all, $1=$ a little, $2=$ quite enough, $3=$ a lot $)$.

\section{The estimation strategy}

We tested the associations between (1) the scores of individual knowledge of pharmaceuticals and the scores of individual knowledge of medicinal plants and (2) the scores of individual use of medicinal plants and the scores of individual use of pharmaceuticals, while controlling for individual variables that have been shown to be associated with knowledge and use of medicinal plants.

We used two types of regressions to ensure robustness: ordinary least-squares and a two-stage instrumental variable model (Deaton, 1997). Following a common trend and after having carried formal tests for their appropriateness, we used a parental attribute (i.e., maternal knowledge of pharmaceuticals) as an instrument to control for the endogeneity of the explanatory variable in our estimates (Angrist \& Krueger, 2001). Endogeneity refers to biases from possible reverse causality, omission of important third variables, and random measurement error (Angrist \& Krueger, 2001). Suppose that some informants are less healthy than the average. Those informants might acquire more knowledge in the use of medicinal plants and in the use of pharmaceuticals. If we do not control for these types of unobserved heterogeneities we would overstate the effect of the use of pharmaceuticals on the use of medicinal plants. In our estimations, we correct for endogeneity biases with the use of instrumental variables, or variables that bear a strong statistical association with the instrumented endogenous variable (the explanatory) but not with the dependent variable (Angrist \& Krueger, 2001).

To ease the interpretation of results, we took the natural logarithm of both the outcome variable (dependent variable) and explanatory variables, so the estimated coefficients can be read as elasticities (percentage change in the outcome variable when the explanatory variable increases one percent). The statistical significance of the estimated association when using the logarithm resembles results from a model with raw data. We use a similar model to test the potential association between the use of medicinal plants (outcome variable) and pharmaceuticals (explanatory variable).

\section{Potential biases in estimations}

A main limitation of this study is the small and homogeneous sample size. Our sample size consists of 136 people from only one community. The small sample size makes it hard to detect small but existing associations between the dependent and the independent variables because it lowers statistical power and increases type II errors. Additionally, because our entire sample comes from the same community, our analysis might misrepresent phenomena that occur at a larger scale. Therefore, our results might not be generalizable unless they are reproduced by other case studies.

Potential sources of biases relate to measurement error and omitted variables. Our measures of use of medicinal plants and pharmaceuticals may contain random measurement error as these are based on self-report of yes/no responses. For example respondents may have better memory than others and some respondents may have wanted to please the interviewer by giving him a positive answer.

Moreover, the pharmaceuticals included in the questionnaire were not randomly selected and this could have introduced a measurement error resulting in less observed variation among informants.
Finally, our measure of knowledge of medicinal plants may be biased toward common knowledge and penalize specialized knowledge, as we based our answer key on the range of uses shared at community level. Random measurement error would inflate standard errors and weaken the statistical results of the analysis, thus making our estimates more conservative.

There may be omitted variables in our models that may have both an effect on the knowledge and use of medicinal plants and on some of our independent variables. For example respondents may have shared the household with a traditional healer or with someone trained as a biomedical health promoter. Respondents who may have experienced more medical problems, either personally or within their household, may also have used both more medicinal plants and pharmaceuticals. Omitted variables can bias both positively and negatively the coefficients of the estimated parameters and inflate the standard errors.

\section{Results}

\section{Descriptive statistics of outcome and explanatory variables}

Knowledge and use of medicinal plants and pharmaceuticals

Definitions and descriptive analysis of the variables are shown in Table 1. The values of Cronbach's alpha for our scores on the tests of knowledge and use of medicinal plants and pharmaceuticals suggest that responses to questions in our tests have high internal consistency. Since we corrected for guessing, the total score on the tests of knowledge are negative when the wrong answers on the test are more than the right ones. We transformed the four scores in order to have the minimum value at one without reducing the sample size when taking the natural logarithm. We transformed the individual scores on the test of knowledge and use of medicinal plants and the scores on the use of pharmaceuticals by adding one. We transformed the scores of knowledge of pharmaceuticals by adding eight.

We found a correlation coefficient of $0.13(p=0.14)$ among the scores of knowledge and use of medicinal plants and a correlation coefficient of $0.43(p<0.01)$ between the scores of knowledge and use of pharmaceuticals (data not shown).

\section{Formal tests for the appropriateness of the instrumental variables (IV)}

In the formal tests for the appropriateness of maternal knowledge of pharmaceuticals as instrumental variables for own knowledge and use of pharmaceuticals (Table 2) we found a significant association between maternal knowledge of pharmaceuticals and own knowledge and use of pharmaceuticals (regressions $\mathrm{V}$ to $\mathrm{VIII}$ ), but not between maternal knowledge of pharmaceuticals and own knowledge and use of medicinal plants (regressions I to IV). Therefore, we consider maternal knowledge of pharmaceuticals to be a valid instrument (instrumental variable) for own knowledge and use of pharmaceuticals.

\section{Multiple regressions}

\section{Knowledge of medicinal plants}

Table 3 shows the results of the multiple regressions where we tested for a possible association between knowledge of medicinal plants (outcome) and knowledge of pharmaceuticals (explanatory variable) with three different combinations of control variables (regressions I to III). We also ran three regressions with maternal knowledge of pharmaceuticals as instrument for own knowledge of pharmaceuticals (also referred in the text as "two-stage leastsquares regressions" or "instrumenting own knowledge of pharmaceuticals") (regression IV-VI). 
Table 1

Definition and descriptive statistics of the variables used in the regression analysis.

\begin{tabular}{|c|c|c|c|c|c|c|c|}
\hline Variable & Definition & $N$ & Mean & Std dev & Min & Max & Cronbach's alpha \\
\hline \multicolumn{8}{|l|}{ Dependent variables } \\
\hline Knowledge of medicinal plants & $\begin{array}{l}\text { Theoretical knowledge of } 15 \text { medicinal plants using } \\
\text { formula scoring and correcting for guessing }\end{array}$ & 136 & 19.37 & 7.86 & 0 & 35 & 0.89 \\
\hline Use of medicinal plants & Self-reported use of 15 medicinal plants & 134 & 7.72 & 3.90 & 0 & 15 & 0.83 \\
\hline \multicolumn{8}{|l|}{ Explanatory variables } \\
\hline Knowledge of pharmaceuticals & $\begin{array}{l}\text { Theoretical knowledge of } 14 \text { pharmaceuticals using } \\
\text { formula scoring and correcting for guessing }\end{array}$ & 136 & 10.78 & 8.43 & -7 & 37 & 0.85 \\
\hline Use of pharmaceuticals & Self-reported use of 14 pharmaceuticals & 131 & 7.05 & 3.10 & 0 & 14 & 0.78 \\
\hline \multicolumn{8}{|l|}{ Control variables } \\
\hline Age & Age in years at the time of the interview & 136 & 47.5 & 14.5 & 20.9 & 92.1 & \\
\hline Male & Dummy variable Male $=1 ;$ Female $=0$ & 136 & 0.49 & 0.5 & 0 & 1 & \\
\hline Schooling & Number of school years completed & 136 & 2.1 & 2.49 & 0 & 12 & \\
\hline Spanish & $\begin{array}{l}\text { Spanish level as assessed by the interviewer at the } \\
\text { end on the questionnaire: }(0,1 \text { or } 2)\end{array}$ & 133 & 1.21 & 0.92 & 0 & 2 & \\
\hline Income & $\begin{array}{l}\text { Kg of coffee sold last year multiplied for average } \\
\text { price ( } 14 \text { MX pesos) }\end{array}$ & 126 & 2388 & 3319 & 0 & 21000 & \\
\hline
\end{tabular}

In three of the six regressions we found a positive and statistically significant association between knowledge of medicinal plants and knowledge of pharmaceuticals. In regressions I to III, the coefficient of knowledge of pharmaceuticals ranges from 0.342 to 0.387 and is statistically significant at the $95 \%$ confidence level. Since the outcome and the explanatory variables are in logarithms, the coefficient can be read as elasticity (a one percent increase in the explanatory variable is associated to a percentage increase in the outcome of the magnitude of the coefficient). In other words, if we have two individuals, $\mathrm{A}$ and $\mathrm{B}$, with similar demographic and socioeconomic characteristics, these models predict that if individual A has $10 \%$ higher score in knowledge of pharmaceuticals than individual B, then individual A will also have 3.4-3.9\% higher score in knowledge of medicinal plants than individual B. Strikingly, this result is contrary to our prediction of a negative association between knowledge of medicinal plants and knowledge of pharmaceuticals. The association disappears when we instrument knowledge of pharmaceuticals (regression IV, V, VI).

In all the models (I-VI) we also found a positive and statistically significant association between knowledge of medicinal plants and age. In these regressions, the coefficient for age is about 0.01 . This means that the average informant would have about $1.0 \%$ higher score of knowledge of medicinal plants than an informant with the same characteristics and one year younger.
A considerable effect, as assuming a linear association, the model would then predict that an average 60 years old person would have about $40 \%$ more knowledge of medicinal plants than a 20 years old average informant.

\section{Use of medicinal plants}

The regressions in Table 4 resemble those from Table 3 except that we include the use of medicinal plants as the outcome variable and the use of pharmaceuticals as the explanatory variable. In the first three models, without instrumental variables, we found that use of pharmaceuticals bore a positive and statistically significant association with the use of medicinal plants. More specifically, a $10 \%$ increase in the use of pharmaceuticals is associated with a $5.1-5.9 \%$ increase in our measure of use of medicinal plants. Similar to what we found for the knowledge of medicinal plants, the sign of the association is contrary to what we expected. In the three instrumental variable regressions (Model IV, V and VI) the association between the use of medicinal plants and the use of pharmaceuticals losses its significance after we instrument use of pharmaceuticals with maternal knowledge of pharmaceuticals.

Similar to the models in Table 3, age is positively associated with the use of medicinal plants. The models predict that the average informant's score of use of medicinal plants would increase between 1 and $1.3 \%$ for every year of age.

Table 2

Testing the adequacy of maternal knowledge of pharmaceuticals as instrumental variable for own knowledge of pharmaceuticals and own use of pharmaceuticals. Columns I-VIII corresponds to the regressions run. Coefficient values of the regression equation are shown in the cells.

\begin{tabular}{|c|c|c|c|c|c|c|c|c|}
\hline \multicolumn{9}{|c|}{ Dependent variables (in natural logarithm) } \\
\hline & I & II & III & IV & $\mathrm{V}$ & VI & VII & VIII \\
\hline & \multicolumn{2}{|c|}{$\begin{array}{l}\text { Knowledge of } \\
\text { medicinal plants }\end{array}$} & \multicolumn{2}{|c|}{ Use of medicinal plants } & \multicolumn{2}{|c|}{$\begin{array}{l}\text { Knowledge of } \\
\text { pharmaceuticals }\end{array}$} & \multicolumn{2}{|c|}{ Use of pharmaceuticals } \\
\hline \multicolumn{9}{|l|}{$\begin{array}{l}\text { Explanatory variables: } \\
\text { Instrumental variable }\end{array}$} \\
\hline $\begin{array}{l}\text { Maternal knowledge of } \\
\text { pharmaceuticals (raw value) }\end{array}$ & 0.085 & 0.085 & 0.130 & 0.135 & $0.199^{* * *}$ & $0.195^{* * *}$ & $0.244^{* * *}$ & $0.246^{* * *}$ \\
\hline \multicolumn{9}{|l|}{ Controls } \\
\hline Age & 0.005 & 0.005 & $0.012^{* *}$ & $0.012^{* * *}$ & $-0.011^{* * *}$ & $-0.012^{* * *}$ & -0.002 & -0.002 \\
\hline Sex & -0.014 & $\mathrm{X}$ & 0.093 & $\mathrm{X}$ & -0.070 & $\mathrm{X}$ & 0.061 & $\mathrm{X}$ \\
\hline Observations & 130 & 130 & 128 & 128 & 130 & 130 & 126 & 126 \\
\hline R-square & 0.0203 & 0.0201 & 0.0899 & 0.0838 & 0.1649 & 0.1614 & 0.1043 & 0.1006 \\
\hline
\end{tabular}

*** and ${ }^{* *}$ significant at $\leq 1 \%$ and $\leq 5 \%$. Regressions are Ordinary Least Square linear regressions with robust standard errors. 
Table 3

Regression results. Columns I to VI corresponds to the regressions run. Coefficient values of the regression equation are shown in the cells. A cell with X means that the variable was intentionally excluded from the regression.

\begin{tabular}{|c|c|c|c|c|c|c|}
\hline & \multicolumn{6}{|c|}{ Dependent variable $=$ Knowledge of medicinal plants (in natural logarithm) } \\
\hline & \multicolumn{6}{|c|}{ Regressions } \\
\hline & I & II & III & IV & $\mathrm{V}$ & VI \\
\hline \multicolumn{7}{|l|}{ Explanatory variable } \\
\hline Pharmaceuticals knowledge (in logarithms) & $0.387 * * *$ & $0.332^{* * *}$ & $0.342 * * *$ & 0.429 & 0.285 & 0.329 \\
\hline \multicolumn{7}{|l|}{ Control variables } \\
\hline Age (years) & $0.010^{* * *}$ & $0.011^{* * *}$ & $0.011^{* * *}$ & $0.010^{* *}$ & $0.010 * * *$ & $0.010^{* *}$ \\
\hline Male (dummy, male $=1$ ) & 0.015 & -0.018 & 0.008 & 0.015 & -0.027 & 0.006 \\
\hline Schooling (Years) & $\mathrm{X}$ & 0.009 & 0.010 & $\mathrm{X}$ & 0.009 & 0.007 \\
\hline Spanish $(0,1$ or 2$)$ & $\mathrm{X}$ & 0.070 & 0.076 & $\mathrm{X}$ & 0.077 & 0.081 \\
\hline Income ( 1 unit $=10000 \mathrm{Mx}$ pesos $)$ & $\mathrm{X}$ & $\mathrm{X}$ & 0.086 & $\mathrm{X}$ & $\mathrm{X}$ & 0.112 \\
\hline IV (mother knowledge of pharmaceuticals) & No & No & No & Yes & Yes & Yes \\
\hline R-square & 0.1796 & 0.1876 & 0.2153 & 0.1806 & 0.1871 & 0.2168 \\
\hline Observations & 136 & 133 & 125 & 130 & 128 & 121 \\
\hline
\end{tabular}

*** and ${ }^{* *}$ significant at $\leq 1 \%$ and $\leq 5 \%$. Regressions are Ordinary Least Square linear regressions with robust standard errors.

Schooling bore a significant negative association with the use of medicinal plants in all the models. The coefficients of the association range from -0.048 to -0.060 . Therefore, the models predict that every year of school completed is associated with a $4.8-6.0 \%$ lower score on the test for use of medicinal plants. Accordingly, an individual who completed secondary school (nine years of school) would have $43.2-54 \%$ lower score on the use of medicinal plants than an individual with no formal education. In other words, we found that schooling is associated with a decrease of use of medicinal plants.

\section{Robustness}

To test the robustness of our results, we ran the regressions in Tables 3 and 4 with the following changes (results not shown): (1) we used knowledge of the folk name of the medicinal plants as a measure of knowledge of medicinal plants and knowledge of commercial name of the pharmaceuticals as measure of the knowledge of pharmaceuticals, (2) we used the raw scores of knowledge and use of medicines instead of logarithms, (3) we added to each regression, separately, control variables for household size, a measure of belief of supernatural causes of illness (number of visits to a traditional healer in the last year) and a measure of migration (years lived outside of the Sierra Mazateca). In all of the robustness tests, the sign, magnitude, and significance of the associations between the explanatory variable and the outcome resemble those presented in Tables 3 and 4 .

\section{Discussion and conclusion}

The first important finding of this study is the significant positive associations between an individual's knowledge of medicinal plants and the same individual's knowledge of pharmaceuticals, as well as between her use of medicinal plants and her use of pharmaceuticals.

The finding suggests that in the study area laypeople who know and use more medicinal plants also know and use more pharmaceuticals, and vice versa.

To better understand this finding we should look at how Mazatecs perceive the two types of medicine and how this perception influences their therapeutic behavior. To Mazatecs, medicine is used in order to fight illness, or its ultimate causes, and to stop the progression to death and restore health. Therapy and treatment are active processes that people carry out against illness. Although Mazatecs distinguish at a cognitive level between medicinal plants (Xka-Xki) and "medicine from the shop" (Xki-tienda) our ethnographic data suggest that use of both types of medicines is not guided by this distinction but rather by perceived efficacy, cost, and access of the medicines. Indeed, self-treatment is the most common therapeutic choice among Mazatecs and the concomitant and complementary use of medicinal plants and pharmaceutical is widespread, also to treat the same conditions. In fact, Mazatecs tend first to use medicinal plants to treat an illness perceived as common and curable. Then, if the patient does not respond to treatment, they

Table 4

Regression results. Columns I to VI corresponds to the regressions run. Coefficient values of the regression equation are shown in the cells. A cell with X means that the variable was excluded from the regression.

\begin{tabular}{|c|c|c|c|c|c|c|}
\hline & \multicolumn{6}{|c|}{ Dependent variable $=$ use of medicinal plants (in natural logarithm) } \\
\hline & \multicolumn{6}{|c|}{ Regressions } \\
\hline & I & II & III & IV & $\mathrm{V}$ & VI \\
\hline \multicolumn{7}{|l|}{ Explanatory variable } \\
\hline Use of pharmaceuticals (in logarithms) & $0.513^{* * *}$ & $0.588^{* * *}$ & $0.585^{* * *}$ & 0.632 & 0.678 & 0.790 \\
\hline \multicolumn{7}{|l|}{ Control variables } \\
\hline Age (years) & $0.013^{* * *}$ & $0.011^{* * *}$ & $0.011^{* * *}$ & $0.013^{* * *}$ & $0.010^{* *}$ & $0.011^{* *}$ \\
\hline Male (dummy, male $=1$ ) & 0.060 & 0.090 & 0.105 & 0.060 & 0.102 & 0.113 \\
\hline Schooling (years) & $\mathrm{X}$ & $-0.050 * * *$ & $-0.048^{* * *}$ & $\mathrm{X}$ & $-0.056^{* *}$ & $-0.060^{* *}$ \\
\hline Spanish $(0,1$ or 2$)$ & $\mathrm{X}$ & 0.011 & 0.030 & $\mathrm{X}$ & 0.004 & 0.004 \\
\hline Income ( 1 unit $=10000 \mathrm{Mx}$ pesos $)$ & $\mathrm{X}$ & $\mathrm{X}$ & 0.003 & $\mathrm{X}$ & $\mathrm{X}$ & -0.001 \\
\hline IV (maternal knowledge of pharmaceuticals) & No & No & No & Yes & Yes & Yes \\
\hline R-square & 0.257 & 0.2877 & 0.288 & 0.2454 & 0.2826 & 0.2635 \\
\hline Observations & 129 & 128 & 122 & 124 & 123 & 118 \\
\hline
\end{tabular}

*** and ${ }^{* *}$ significant at $\leq 1 \%$ and $\leq 5 \%$. Regressions are Ordinary Least Square linear regressions with robust standard errors. 
use pharmaceuticals. In other words, medicinal plant and pharmaceuticals are seen, and used, as options of the same health care system in the study site (Giovannini \& Heinrich, 2009).

This finding dovetails with previous research emphasizing the complementarities of traditional medicine and biomedicine as available health care options (Kleinman, 1980; Leslie, 1980; Worsley, 1982).Furthermore, it dovetails with Mexico's long history of medical pluralism. During the colonial period many indigenous cosmological beliefs about health and sickness were lost or transformed by missionary activity. However, the Spanish were greatly interested in the medicinal plants of the New World and incorporated many indigenous medicinal plants into colonial medicine (Ortiz De Montellano, 1990). Likewise, European materia medica was added to indigenous pharmacopoeias. In modern times, the use of the same medicinal plants (both introduced and native species) for related disease conditions is common among Mexican mestizos and Mexican Americans, as well as numerous indigenous Mexican groups (Heinrich, Ankli, Frei, Weimann, \& Sticher, 1998; Kay, 1977). The acceptance of pharmaceuticals among the Mazatecs may thus, be interpreted as part of the continuing adoption of new medicines into indigenous Mexican pharmacopoeias, which has been documented since colonial times.

Our second important finding is that the estimated association between knowledge of medicinal plants and knowledge of pharmaceuticals, as well as between use of medicinal plants and use of pharmaceuticals, disappears after we control for endogeneity. This finding suggests that these associations are not causal but rather may reflect the role of third unobserved variables. We suggest that potential third unobserved variables are an individual's interest in medicine and/or frequency of self-medication. Indeed, ethnographic evidence suggests that Mazatecs recognize that among laypeople there are some individuals that hold more medical knowledge than others. It is possible that these individuals had more exposure to medical knowledge in their household or that they become responsible for the health of other members of their household. These individuals have more interest in medical knowledge than others, and - pragmatically - this interest encompasses knowledge and use of both medicinal plants and pharmaceuticals, provided that the Mazatecs consider those two types of medicines as useful and efficacious in maintaining or restoring health. For example, one informant explained that her father was a traditional healer and that he taught her how to use both medicinal plants and pharmaceuticals. Again, this suggests that Mazatecs see medicinal plants and pharmaceuticals as options of the same health care system in the study site.

One should note that while our findings indicate that medicinal plants and pharmaceuticals are co-existing, they do not exclude the possibility that knowledge of medicinal plants may have changed or transformed in the last decades. On the contrary, it is possible that with the increasing migration outside the region some new knowledge about medicinal plants has been added and other knowledge may have been lost.

Our third finding, that schooling has a negative association with the use of medicinal plants, suggests that the social organization of the Mazatecs is of particular significance concerning the erosion of the knowledge and use medicinal plants. Previous research on the effect of schooling on traditional ecological knowledge, including knowledge of medicinal plants, shows that the two are often negatively associated, especially if schools curricula are not contextualized (Quinlan \& Quinlan, 2007; ReyesGarcía et al., 2010; Sternberg et al., 2001). Indeed, in the study site, school curricula are poorly adapted to the rural context and the teachers are often coming from more urbanized areas. For example, the secondary school uses a system of via satellite distance education, which broadcasts the same curricula for all rural communities in Mexico, and the textbooks included culturally inappropriate content such as, for example, an English text about the life of a US millionaire.

Some authors suggest that children attending school have less time to learn empirical ecological knowledge (Reyes-García et al., 2010; Sternberg et al., 2001). It is possible that as younger generations are acculturated by state-run institutions (i.e. schools) a growing dependence on professional medical services may potentiate a decline in the use of home remedies of both traditional and biomedical origin. In other words, the increased exposure to global capitalist culture (including its highly professionalized biomedical system) and decreased contact with the local environment due to attending state-run schools could ultimately lead to a re-organization of the way medical knowledge is distributed and healthcare is provided in a community.

One last finding deserves attention. We found that age is positively associated with both knowledge and use of medicinal plants. The finding is in agreement with previous empirical research on traditional ecological knowledge (Phillips \& Gentry, 1993; Voeks, 2007). The association does not necessarily imply an on-going loss of knowledge between generations. Rather, it can be explained by the fact that people continue learning about medicinal plants during their lifetime and as a consequence their knowledge and use about them increases (Quinlan \& Quinlan, 2007). It is also possible that the observed association is caused by the fact that when people get older they are more likely to get ill and/or become responsible for the health of other members of the household, so they acquire more knowledge on medicinal plants and pharmaceuticals.

In conclusion, our study suggests that, at individual level, knowledge and use of medicinal plants and pharmaceuticals coexist. We did not find evidence of competition between these two systems of knowledge and practice. Future studies on the relationships between knowledge of medicinal plants and pharmaceuticals should:

1) include a measurement of general interest on medical knowledge as a whole rather than separating interest toward traditional medicine and biomedicine

2) include instrumental variables to distinguish between real causality and the effect of omitted variable bias (see the estimation strategy section)

3) address social factors (like schooling) in more detail.

Effective policy to improve health care systems should consider the contemporaneous and integrated use of traditional medicine and biomedicine as part of a continuum range of available options for self-medication. Finally, policy makers and researchers should also consider the potential physiological interactions between the concomitant use of plants and pharmaceuticals.

\section{Acknowledgments}

We express our profound gratitude to any Mazatec people, especially to the inhabitants of the community where this research was conducted. Thanks to Laurecio López Nuñez and Enriqueta Martinez Murillo from CECIPROC. Thanks to Marco Antonio Vásquez from I.T.V.O. in Oaxaca, Mexico. Thanks to Miguel A. Martínez Alfaro, Abigail Aguilar, Alberto Ysunza Ogazón, Silvia Diaz-Urdanivia for help during the fieldwork period. Thanks to the director of the MEXU Gerardo A. Salazar and to all the staff for help and technical assistance to identify voucher specimens. Thanks to five anonymous reviewers that helped to improve this paper. 


\section{Appendix 1}

List of the plant species selected for the survey to assess knowledge of medicinal plants

\begin{tabular}{l}
\hline Medicinal plants used in the survey \\
\hline Ageratum corymbosum Zuccagni \\
Bursera simaruba (L.) Sarg. \\
Cedrela odorata L. \\
Phlebodium areolatum (Humb. \& Bompl. Ex Willd) J. Sm. \\
Abelmoschus moschatus Medik. \\
Croton draco Schltdl. \& Cham. \\
Eupatorium morifolium Mill. \\
Matricaria recutita L. \\
Neurolaena macrocephala Sch. Bip. Ex Hemsl. \\
Solenostenom scutellarioides L. \\
Persea americana Mill. \\
Pilea microphylla (L.) Liebm. \\
Trimezia steyermarkii R.C. Foster \\
Tournefortia glabra L. \\
Valeriana scandens L.
\end{tabular}

\section{Appendix 2}

List of pharmaceuticals used during the survey to assess knowledge of pharmaceuticals.

\begin{tabular}{l}
\hline Pharmaceuticals selected for the survey \\
\hline NEO-MELUBRINA ${ }^{\circledR}$ \\
$666^{\circledR}$ \\
Penicilina \\
Metronidazol $^{\circledR}$ \\
Ampicilina \\
Aspirina \\
Bicarbonato $^{\circledR}$ \\
Cafi-Aspirina $^{\circledR}$ \\
Mejoral $^{\circledR}$ \\
Mertiolate $^{\circledR}$ \\
Micotex $^{\circledR}$ \\
Penprocilina $^{(}$ \\
Respicil $^{\circledR}$ \\
Pepto-bismol $^{\circledR}$
\end{tabular}

\section{References}

Ackerknecht, E. (1942). Problems of primitive medicine. Bulletin of the History of Medicine, 11, 503-521.

Angoff, W. H., \& Schrader, W. B. (1984). A study of hypotheses basic to the use of rights and formula scores. Journal of Educational Measurement, 21(1), 1-17.

Angrist, J. D., \& Krueger, A. B. (2001). Instrumental variables and the search for identification: from supply and demand to natural experiments. Journal of Economic Perspectives, 15(4), 69-85.

Berlin, B. (1992). Ethnobiological classification: Principles of categorization of plants and animals in traditional societies. Princeton: Princeton University Press.

Berlin, E.-A., \& Berlin, B. (2005). Some field methods in medical ethnobiology. Field Methods, 17(3), 235-268.

Bland, J. M., \& Altman, D. G. (1997). Statistics notes: Cronbach's alpha. British Medical Journal, 314, 572.

Boege, E. (1988). Los Mazatecos ante la nación. Mexico, D.F.: Siglo Veintiuno Editores.

Boster, J. (1985). Requiem for the omniscient informant: There's life in the old gir yet. In J. Dugherty (Ed.), Directions in cognitive anthropology (pp. 177-197). Urbana: University of Illinois Press

Byg, A., Salick, J., \& Law, W. (2010). Medicinal plant knowledge among lay people in five eastern Tibet villages. Human Ecology, 38(2), 177-191.

Cabrera, A., Inchaustegui, C., Garcia, A., \& Toledeo, V. (2001). Etnoecologia Mazateca: una approcimacion al complejo cosmus-corpus-praxis. Etnoecologica, 6, 61-83.

Calvet-Mir, L., Reyes-García, V., \& Tanner, S. (2008). Is there a divide between local medicinal knowledge and Western medicine? A case study among native Amazonians in Bolivia. Journal of Ethnobiology and Ethnomedicine, 4, 18.
Caniago, I., \& Siebert, S. F. (1998). Medicinal plant ecology, knowledge and conservation in Kalimantan, Indonesia 1. Economic Botany, 52(3), 229-250.

Carranza, R. (2005). Vademecum Academico de Medicamentos. Mexico D.F: McGrawHill. Facultad de Medicina UNAM.

Deaton, A. (1997). The analysis of household surveys. Microeconomic analysis for development policy. Baltimore: John Hopkins University Press.

Etkin, N., Ross, P., \& Muazzamu, I. (1990). The indigenization of pharmaceuticals: therapeutic transitions in rural Hausaland. Social Science $\mathcal{E}$ Medicine, 30(8), 919-928.

Foster, G., \& Anderson, B. (1978). Medical anthropology. New York: John Wiley and Sons.

Giovannini, P., \& Heinrich, M. (2009). Xki yoma' (our medicine) and xki tienda (patent medicine)-interface between traditional and modern medicine among the Mazatecs of Oaxaca, Mexico. Journal of Ethnopharmacology, 121(3), 383-399.

Heinrich, M., Ankli, A., Frei, B., Weimann, C., \& Sticher, O. (1998). Medicinal plants in Mexico: healers' consensus and cultural importance. Social Science E Medicine, 47(11), 1863-1875.

Hoa, N. P., Chuc, N. T., \& Thorson, A. (2009). Knowledge, attitudes, and practices about tuberculosis and choice of communication channels in a rural community in Vietnam. Health Policy, 90, 8-12.

Kay, M. A. (1977). The Florilegio medicinal: source of southwest ethnomedicine. Ethnohistory, 24(3), 251-259.

Kleinman, A. (1980). Patients and healers in the context of culture: An exploration between anthropology, medicine and psychiatry. Berkeley: University of California Press.

Leslie, C. (1980). Medical pluralism in world perspective. Social Science Er Medicine. Part B: Medical Anthropology, 14(4), 191-195.

Martin, G. (2004). Ethnobotany. A methods manual. London: Chapman and Hall.

Muela, S. H., Ribera, J. M., Mushi, A. K., \& Tanner, M. (2002). Medical syncretism with reference to malaria in a Tanzanian community. Social Science \&'Medicine, 55(3), 403-413.

Ngokwey, N. (1995). Home remedies and doctors remedies in Feira (Brazil). Socia Science E Medicine, 40(8), 1141-1153.

Ortiz De Montellano, B. (1990). Aztec medicine, health, and nutrition. New Brunswick: Rutgers University Press.

Phillips, O., \& Gentry, A. (1993). The useful plants of Tambopata, Peru: II. Additional hypothesis testing in quantitative ethnobotany. Economic Botany, 47(1), 33-43.

Quinlan, M. B., \& Quinlan, R. J. (2007). Modernization and medicinal plant knowledge in a Caribbean horticultural village. Medical Anthropology, 21(2), 169-192.

Ragupathy, S. Steven, N. G. Maruthakkutti, M. Velusamy, B. \& Ul-Huda, M. M. (2008). Consensus of the 'Malasars' traditional aboriginal knowledge of medicinal plants in the Velliangiri holy hills, India. Journal of Ethnobiology and Ethnomedicine, 4, 8.

Reyes-García, V., Godoy, R., Vadez, V., Apaza, L., Byron, E., Huanca, T., et al. (2003) Ethnobotanical knowledge shared widely among Tsimane' Amerindians, Bolivia. Science, 299(5613), 1707.

Reyes-García, V., Kightley, E., Ruiz-Mallén, I., Fuentes-Peláez, N., Demps, K. Huanca, T., et al. (2010). Schooling and local environmental knowledge: do they complement or substitute each other? International Journal of Educational Development, 30(3), 305-313.

Saethre, E. J. (2007). Conflicting traditions, concurrent treatment: medical pluralism in remote aboriginal Australia. Oceania, 77(1), 95-110.

Scrimshaw, M., \& Cosminsky, S. (1980). Medical pluralism on a Guatemalan plantation. Social Science \& Medicine. Part B: Medical Anthropology, 14(4), 267-278.

Spring, A. (1980). Faith and participation in traditional versus cosmopolitan medical systems in Northwest Zambia. Anthropological Quarterly, 53(2), 130-141.

Sternberg, R., Nokes, C., Geissler, P., Prince, R., Okatcha, F., Bundy, D., et al. (2001) The relationship between academic and practical intelligence: a case study in Kenya. Intelligence, 29, 401-418.

Swiss Pharmaceutical Society. (2004). Index Nominum. International drug directory. Stuttgart: Medpharm Scientific publishers.

UNAM. (2007). Dicionario de especialidades farmaceuticas. Mexico D.F.: Facultad de Medicina UNAM.

Vandebroek, I., Calewaert, J., De jonckheere, S., Sanca, S., Semo, L., Van Damme, P., et al. (2004). Use of medicinal plants and pharmaceuticals by indigenous communities in the Bolivian Andes and Amazon. Bulletin of the World Health Organization, 82(4), 243-250.

Voeks, R. A. (2007). Are women reservoirs of traditional plant knowledge? Gender ethnobotany and globalization in northeast Brazil. Singapore Journal of Tropical Geography, 28(1), 7-20.

WHO. (2008). Traditional medicine. Fact sheet $N^{\circ} 134$. Geneva: WHO. http://www. who.int/mediacentre/factsheets/fs134/en/print.html Retrieved from.

Worsley, P. (1982). Non-western medical systems. Annual Review of Anthropology, 11 (1), 315-348 